\title{
Dyslipidaemia is common among patients with type 2 diabetes: a cross-sectional study at Tema Port Clinic
}

\author{
Emmanuel Kwaku Ofori ${ }^{*}$, Dorcas Owusu-Ababio ${ }^{2}$, Emmanuel A. Tagoe ${ }^{3}$ and Henry Asare-Anane ${ }^{1}$
}

\begin{abstract}
Objective: This study aimed to evaluate dyslipidemia in Ghanaian subjects with type 2 diabetes.

Results: Hundred individuals with type 2 diabetes and 61 apparently healthy controls participated. The prevalence of hypercholesterolemia among persons with type 2 diabetes was $53 \%$. Blood pressure, fasting blood glucose (FBG), triglyceride $(T G)$, low-density lipoproteins $(\mathrm{LDL})$ and alanine transaminase (ALT) levels were higher in persons with type 2 diabetes compared with the control group $(p<0.01)$. Positive correlations were found within persons with type 2 diabetes for triglyceride vs FBG; ALT vs age and aspartate transaminase (AST) vs TG ( $p<0.05$ respectively). This study demonstrated hyperlipidemia and poor liver health in persons with type 2 diabetes.
\end{abstract}

Keywords: Dyslipidemia, Diabetes mellitus, Cardiovascular, Transaminase

\section{Introduction}

Diabetes mellitus has become the fifth leading cause of death globally with increasing prevalence in the developing world $[1,2]$. A prevalence rate of $3.3 \%$ has been estimated among Africans [3]. Uncontrolled diabetes mellitus leads to medical complications that include coronary risks, stroke, and damages to the extremities of the eyes, kidney and the nerves $[4,5]$.

A lipid profile is a direct measure of three blood components namely, total cholesterol ( $\mathrm{T}$. Chol), triglyceride (TG) and high-density lipoprotein (HDL) [6]. Other constituents such as low-density lipoproteins (LDL), atherogenic risk (AR), very low-density lipoproteins (VLDL) and coronary risk (CR) are usually derived from such direct measures [6,7]. Lipid abnormalities have been implicated in the causation of insulin resistance, type 2 diabetes, obesity and atherosclerosis [8-12]. Studies in Ghana (albeit few), have estimated that between 3.3 and $6 \%$ of the general population has diabetes with the prevalence increasing with age and is higher in urban areas

\footnotetext{
*Correspondence: oforiman@yahoo.co.uk

1 Department of Chemical Pathology, School of Biomedical and Allied Health Sciences (S.B.A.H.S.), University of Ghana, Accra, Ghana

Full list of author information is available at the end of the article
}

$[13,14]$. The exodus from rural to urban communities continue to increase in Ghana $[15,16]$. An earlier study at the Korle-Bu Teaching Hospital revealed that cardiovascular diseases (CVDs) constituted more than one-fifth of all causes of death from 2006 to 2010 [17]. Controlling levels of lipids could be a possible way of controlling high blood pressure and prevention of hypertensive nephropathy $[18,19]$. Dyslipidemia may thus be more prevalent and may be playing a major role in the pathogenesis and management of diabetes mellitus. Little is known about the lipid profile pattern of Ghanaian persons with type 2 diabetes. Due to lifestyle risks associated with urbanization [13], this study aimed to evaluate dyslipidemia in Ghanaian patients with type 2 diabetes mellitus reporting at the Tema Port Clinic. It is anticipated that this study will provide information that could help in the management dyslipidemia among Ghanaian subjects.

\section{Main text \\ Methods}

The study design was observational cross-sectional and was carried out at the Tema Port Clinic, Ghana from February 2013 to August 2013. A total of 161 individuals comprising 100 persons with type 2 diabetes and 61 BMImatched apparently healthy staff/workers (controls) from 
the Clinic, were recruited into the study. Sample size of 60 persons was adequate for this study assuming an odds ratio of 2.0 among diabetic subjects for dyslipidemia, at a $5 \%$ significant level and a power of $80 \%$. An oral glucose tolerance test $(\mathrm{FBG} \leq 6.9 \mathrm{mmol} / \mathrm{L}$ and a 2 -h post-prandial $\leq 11.1 \mathrm{mmol} / \mathrm{L}$ ), regarded as diagnostic [2] was performed on all volunteers. The ethical and protocol review committee of Narh-Bita College, Tema, reviewed and approved the study. Detailed explanations on purpose of the study, risk and benefits were made known to participants. In addition to the patient's clinical data retrieved from medical records, a standard questionnaire was used to collect socio-demographic data from consented participants. Height was measured using a wall-mounted stadiometer (Secca, Germany). Body weight was by a standard digital scale (Tanita Corporation, Tokyo, Japan). Body mass index was calculated as weight divided by squared height $\left(\mathrm{kg} / \mathrm{m}^{2}\right)$. Blood pressure was taken using a mercury sphygmomanometer and stethoscope after participants had rested for $15 \mathrm{~min}$. Participants was seated on a chair and the feet firmly rested on the floor. The measurement was taken from the same hand (left) rested on a desk with the antecubital fossa level with the palm facing upwards. High blood pressure was defined as $\mathrm{SBP}>140 \mathrm{mmHg}$ or DBP $>90 \mathrm{mmHg}$ or self-reported controlled treatment using hypertensive medication [20]. Persons with gestational diabetes, human immunodeficiency virus (HIV), Hepatitis B infection, habitual smokers and subjects with stroke or amputation were excluded from the study.

Venous blood $(4 \mathrm{~mL})$ was obtained from the subjects between 07:00 and 09:00 $\mathrm{h}$ each day, after an overnight fast, according to Helsinki protocol declaration [21]. One milliliter of whole blood was transferred into sodium fluoride containing tube and centrifuged, with resulting plasma separated for the estimation of FBG. The remaining blood sample was placed into serum separator tube and processed. Serum was stored at $-20{ }^{\circ} \mathrm{C}$ until required for analysis. Samples were thawed for total cholesterol (T. Chol), triglycerides (TG) and highdensity lipoprotein (HDL) estimations. All analysis were performed using auto-analyzer (Roche-Hitachi Modular Analytics, Tokyo, Japan). Cardiovascular risk was computed as the ratio of T. Chol to HDL and has been described by Wilson et al. [22]. Low-density lipoprotein cholesterol (LDL) was computed as previously described [23]. Liver markers including total proteins (TP), albumin (ALB), aspartate transaminase (AST), alanine transaminase (ALT), gamma-glutamyl transferase (GGT), alkaline phosphatase (ALP), total bilirubin (TBil) and direct bilirubin (DBil) were also analyzed (Roche-Hitachi Modular Analytics, Tokyo, Japan). Dyslipidemia was defined as: T. Chol $(>5.0 \mathrm{mmol} / \mathrm{L})$, LDL-C $(>3.0 \mathrm{mmol} / \mathrm{L})$,
TG $(>1.7 \mathrm{mmol} / \mathrm{L})$ and HDL $(<1.0 \mathrm{mmol} / \mathrm{L}$ for men and $<1.2 \mathrm{mmol} / \mathrm{L}$ for women) [24].

Data were expressed as mean \pm standard deviation and in percentages where appropriate. The Statistical Package for Social Sciences (SPSS) version 20.0 (SPSS Software, San Diego, U.S.A.) was used for analysis. Unpaired student's t-test was used to evaluate differences between two means. Pearson's correlation coefficient ( $r$ ) was used to establish relationship between two continuous variables. Statistical significance was set at $\mathrm{p}<0.05$ for all tests.

\section{Results}

The clinical and biochemical parameters of the study population are shown in Table 1 . The mean ages for persons with diabetes and controls were 51.67 and 42.05 years respectively and were statistically different $(p<0.0001)$. Systolic blood pressure (SBP), diastolic blood pressure (DBP), FBG, T. Chol, TG and ALT levels were respectively higher in persons with type 2 diabetes compared with controls $(p>0.05)$. There were however, no difference $(p>0.05)$ respectively, for BMI, GGT, HDL, ALP, TP and ALB levels between the two study groups. The inter-dependency of several parameters (Age, SBP, DBP, FBG, TG, LDL, T. Chol, TB, ALT and AST) within persons with type 2 diabetes is shown in Table 2. Age correlated negatively with SBP $(r=-0.260, p<0.01)$ whiles positive relationships were found for TG vs FBG $(\mathrm{r}=0.289, \mathrm{p}<0.01)$; ALT vs age $(\mathrm{r}=0.388, \mathrm{p}<0.01)$ and AST vs TG $(r=0.248, p<0.01)$.

\section{Discussion}

This study sought to investigate dyslipidemia in Ghanaian persons with type 2 diabetes. In this study, T. Chol, TG and their derived fractions, were significantly higher in persons with type 2 diabetes compared with controls. This lipid pattern was consistent with other studies implicating dyslipidemia in type 2 diabetes [25, 26]. Although the mechanisms are not fully elucidated, defects in insulin action and hyperglycemia have been shown to alter plasma levels of lipoprotein in patients with type 2 diabetes [27]. The prevalence of hypercholesterolemia in this study was 53\% (not shown). Others have shown prevalence ranging from 30 to $80 \%$ [8, 28-31]. The presence of elevated levels of cholesterol is known to play a key role in both the initiation and progression of atherosclerosis, as well as in other clinical consequences such as myocardial infarction, stroke, peripheral vascular disease, and heart failure [32, 33].

Fasting blood glucose levels associated positively and significantly with triglyceride. In type 2 diabetes, there is both insulin insensitivity and resistance resulting in impaired glucose availability in cells to provide energy. This may be responsible for increased lipolysis resulting 
Table 1 Clinical and biochemical variables of the study population

\begin{tabular}{|c|c|c|c|c|}
\hline Variables & $\begin{array}{l}\text { Type } 2 \text { diabetes } \\
(\mathrm{N}=100)\end{array}$ & $\begin{array}{l}\text { Controls } \\
(\mathrm{N}=61)\end{array}$ & $95 \% \mathrm{Cl}$ & $\begin{array}{l}p \text {-value } \\
(t \text {-test })\end{array}$ \\
\hline Age (years) & $51.67 \pm 9.25$ & $42.05 \pm 7.96$ & -12.85 to $(-6.39)$ & $<0.0001$ \\
\hline BMI $\left(\mathrm{kg} / \mathrm{m}^{2}\right)$ & $28.37 \pm 5.72$ & $28.23 \pm 4.84$ & -7.35 to 4.97 & 0.9241 \\
\hline $\mathrm{SBP}(\mathrm{mmHg})$ & $143.48 \pm 24.97$ & $135.16 \pm 19.98$ & -15.71 to $(-0.92)$ & 0.0288 \\
\hline $\mathrm{DBP}(\mathrm{mmHg})$ & $83.37 \pm 15.06$ & $74.54 \pm 13.51$ & 47.17 to 56.41 & 0.0001 \\
\hline $\mathrm{FBG}(\mathrm{mmol} / \mathrm{L})$ & $11.62 \pm 7.81$ & $5.03 \pm 0.61$ & -8.56 to $(-4.62)$ & $<0.0001$ \\
\hline T. Chol (mmol/L) & $6.13 \pm 0.70$ & $4.58 \pm 0.65$ & -1.76 to $(-1.33)$ & $<0.0001$ \\
\hline $\mathrm{TG}(\mathrm{mmol} / \mathrm{L})$ & $1.57 \pm 1.01$ & $1.04 \pm 0.43$ & -0.79 to $(-0.26)$ & 0.0001 \\
\hline $\mathrm{HDL}(\mathrm{mmol} / \mathrm{L})$ & $1.26 \pm 0.48$ & $1.26 \pm 0.47$ & -0.15 to 0.15 & 1.0000 \\
\hline LDL (mmol/L) & $3.68 \pm 0.96$ & $2.85 \pm 0.86$ & -1.12 to $(-0.53)$ & 0.0001 \\
\hline Cardiovascular risk & $4.88 \pm 1.46$ & $3.54 \pm 1.38$ & -1.79 to $(-0.88)$ & 0.0001 \\
\hline Atherogenic index & $5.89 \pm 1.02$ & $3.18 \pm 0.08$ & -2.96 to $(-2.45)$ & $<0.0001$ \\
\hline Total Bil $(\mu \mathrm{mol} / \mathrm{L})$ & $11.82 \pm 8.43$ & $13.75 \pm 4.97$ & -0.40 to 4.26 & 0.1065 \\
\hline Direct Bil $(\mu \mathrm{mol} / \mathrm{L})$ & $4.42 \pm 2.13$ & $4.35 \pm 2.53$ & -0.79 to 0.65 & 0.8509 \\
\hline Indirect Bil ( $\mu \mathrm{mol} / \mathrm{L})$ & $7.72 \pm 4.00$ & $9.39 \pm 3.92$ & 0.40 to 2.93 & 0.0105 \\
\hline $\mathrm{GGT}(\mathrm{U} / \mathrm{L})$ & $30.45 \pm 18.28$ & $30.43 \pm 11.58$ & -5.04 to 5.20 & 0.9756 \\
\hline ALT (U/L) & $35.04 \pm 21.28$ & $27.85 \pm 9.49$ & -12.85 to $(-1.53)$ & 0.0138 \\
\hline AST (U/L) & $32.60 \pm 6.31$ & $30.36 \pm 7.27$ & -3.93 to $(-0.54)$ & 0.0805 \\
\hline $\operatorname{ALP}(\mathrm{U} / \mathrm{L})$ & $182.82 \pm 64.57$ & $177.50 \pm 52.69$ & -24.54 to 13.90 & 0.5882 \\
\hline Total protein $(\mathrm{g} / \mathrm{L})$ & $65.77 \pm 15.46$ & $68.35 \pm 10.06$ & -1.774 to 6.934 & 0.2473 \\
\hline Albumin (g/L) & $38.32 \pm 7.24$ & $38.60 \pm 5.87$ & -1.87 to 2.43 & 0.7990 \\
\hline Duration of DM (years) & $3.53 \pm 4.72$ & - & - & - \\
\hline
\end{tabular}

Values are given as mean $\pm \mathrm{SD}$. Atherogenic index $=[(\mathrm{TC}-\mathrm{HDL}) / \mathrm{HDL}]$, Cardiovascular risk $=[\mathrm{TC} / \mathrm{HDL}], \mathrm{p}<0.05$ is statistically significant

$S B P$ systolic blood pressure, $D B P$ diastolic blood pressure, $B M I$ body mass index, $T$. Chol total cholesterol, $T G$ is triglyceride, $H D L$ high-density lipoprotein, $L D L$ lowdensity lipoprotein, FBG fasting blood glucose, AST aspartate transaminase, $A L T$ alanine transaminase, GGT gamma-glutamyl transferase, $A L P$ alkaline phosphatase, Bil bilirubin, DM diabetes mellitus

Table 2 Correlation matrix of selected parameters in persons with $\mathbf{2}$ diabetes

\begin{tabular}{|c|c|c|c|c|c|c|c|c|c|c|c|}
\hline & Age & SBP & DBP & FBS & TG & LDL & T. Chol & TB & IB & ALT & AST \\
\hline Age & 1.000 & & & & & & & & & & \\
\hline SBP & -0.260 & 1.000 & & & & & & & & & \\
\hline DBP & -0.091 & 0.642 & 1.000 & & & & & & & & \\
\hline FBS & 0.112 & 0.191 & -0.013 & 1.000 & & & & & & & \\
\hline TG & 0.014 & 0.120 & -0.009 & 0.289 & 1.000 & & & & & & \\
\hline LDL & -0.034 & 0.020 & -0.041 & 0.124 & -0.070 & 1.000 & & & & & \\
\hline T. Chol & 0.078 & 0.107 & 0.110 & -0.032 & 0.011 & 0.297 & 1.000 & & & & \\
\hline TB & 0.009 & -0.031 & 0.045 & 0.005 & 0.081 & -0.005 & -0.055 & 1.000 & & & \\
\hline IB & 0.011 & 0.059 & 0.079 & 0.005 & 0.094 & 0.005 & -0.051 & 0.921 & 1.000 & & \\
\hline ALT & 0.388 & -0.058 & -0.124 & 0.091 & 0.025 & -0.006 & -0.005 & -.007 & 0.040 & 1.000 & \\
\hline AST & 0.133 & -0.024 & -0.067 & -0.078 & 0.248 & 0.099 & -0.017 & 0.100 & 0.118 & -0.008 & 1.000 \\
\hline
\end{tabular}

Values in italic is significant $(p<0.05)$

SBP systolic blood pressure, DBP diastolic blood pressure, $T$. Chol total cholesterol, TG triglyceride, $L D L$ low-density lipoprotein, $F B G$ fasting blood glucose, $A S T$ aspartate transaminase, $A L T$ alanine transaminase, $T B$ total bilirubin, $I B$ indirect bilirubin

in influx of free fatty acids to the liver, which may drive up hepatic triglyceride synthetic rates evidenced in type 2 diabetes [34]. Elevated TG and reduced levels of HDL has been implicated in liver dysfunction and may be attributed to accumulated fatty liver [35, 36]. Improved glycemic control is generally associated with favourable lipoprotein levels and reductions in both TG and T. Chol levels $[27,28]$ via mechanisms that decrease circulating 
very low density lipoproteins [37] and the up regulation of LDL catabolism [38, 39].

The development of lipid abnormalities and cardiovascular diseases in diabetes mellitus have also been suggested to be predicted by several other factors including raised BMI, hypertriglyceridemia, low HDL levels and hypertension. This study however, did not observe significant relationships with several of the above-mentioned metabolic parameters. Non-differences observed could be attributable to different volunteer characteristics and the sampling technique used in subject recruitment which may have introduced a bias. Differences observed for both systolic and diastolic blood pressures between the two study groups was however significant. Chronic glycemic status tend to be associated with increases in both systolic and diastolic blood pressures [40, 41].

In summary, results highlight dyslipidemia in persons with type 2 diabetes with increased circulating lipids affecting liver health. Proper management of diabetes mellitus including lifestyle modifications can reduce dyslipidemia and the risk of cardiovascular disease and liver dysfunction.

\section{Limitations}

This study was not without limitations. This study did not measure plasma insulin concentrations which would have enabled the authors explore associations with insulin resistance. Our data only provide observation of associations but not causality and cannot be generalized to all populations. In addition to larger sample size, future work should consider the role of dyslipidemia in diabetic complications.

\section{Abbreviations \\ FBG: fating blood glucose; TG: triglyceride; ALT: alanine transaminase; AST: aspartate transaminase; HDL: high density lipoprotein; VLDL: very low-density lipoprotein; LDL: low density lipoprotein; CR: coronary risk; CVD: cardiovascular disease; T. Chol: total cholesterol; BMI: body mass index; SBP: systolic blood pressure; DBP: diastolic blood pressure; ALB: albumin; TP: total protein; GGT : gamma-glutamyl transferase; ALP: alkaline phosphatase; HIV: human immu- nodeficiency virus.}

\section{Authors' contributions}

EKO conceptualized and designed the study. EKO, DA and HAA contributed to the draft of the manuscript. DA participated in the recruitment and sampling of subjects. HAA substantively revised the manuscript. EAT analyzed all the data and reviewed the manuscript. All authors read and approved the final manuscript.

\section{Author details}

${ }^{1}$ Department of Chemical Pathology, School of Biomedical and Allied Health Sciences (S.B.A.H.S.), University of Ghana, Accra, Ghana. ${ }^{2}$ Department of Medical Laboratory, Narh-Bita College, Tema, Ghana. ${ }^{3}$ Department of Medical Laboratory, S.B.A.H.S, University of Ghana, Accra, Ghana.

\section{Acknowledgements}

The authors acknowledge the Diabetes Unit of the Tema Port Clinic for the use of their facility and the Narh-Bita College of Health Sciences for institutional support.

\section{Competing interests}

The authors declare that they have no competing interests.

\section{Availability of data and materials}

The datasets used and/or analysed during the current study are available from the corresponding author on reasonable request.

\section{Consent for publication}

Not applicable.

\section{Ethics approval and consent to participate}

The study was approved by the Institutional Ethics and Protocol Review Committee of Narh-Bita College of Health Sciences, Tema. Detailed explanations on purpose of the study, risk and benefits were made known to participants. Written informed consent was obtained from all participants.

\section{Funding}

No funding was received for this project.

\section{Publisher's Note}

Springer Nature remains neutral with regard to jurisdictional claims in published maps and institutional affiliations.

Received: 15 February 2019 Accepted: 1 April 2019

Published online: 03 April 2019

\section{References}

1. Adeghate E, Schattner P, Dunn E. An update on the etiology and epidemiology of diabetes mellitus. Ann N Y Acad Sci. 2006;1084(1):1-29.

2. Association AD. Standards of medical care in diabetes-2014. Diabetes Care. 2014;37(Supplement 1):S14-80.

3. Ogurtsova K, et al. IDF Diabetes Atlas: global estimates for the prevalence of diabetes for 2015 and 2040. Diabetes Res Clin Pract. 2017; 128:40-50.

4. Zimmet P, Alberti K, Shaw J. Global and societal implications of the diabetes epidemic. Nature. 2001;414(6865):782.

5. Shaw JE, Sicree RA, Zimmet PZ. Global estimates of the prevalence of diabetes for 2010 and 2030. Diabetes Res Clin Pract. 2010;87(1):4-14.

6. Risérus U, Willett WC, Hu FB. Dietary fats and prevention of type 2 diabetes. Prog Lipid Res. 2009;48(1):44-51.

7. Nigam P. Serum lipid profile: fasting or non-fasting? Indian J Clin Biochem. 2011;26(1):96-7.

8. Bhatnagar D, Soran H, Durrington PN. Hypercholesterolaemia and its management. BMJ. 2008;337:a993.

9. Hussain A, Ali I, ljaz M, Rahim A. Correlation between hemoglobin A1C and serum lipid profile in Afghani patients with type 2 diabetes: hemoglobin A1c prognosticates dyslipidemia. Ther Adv Endocrinol Metab. 2017:8(4):51-7.

10. Eastman $\mathrm{RC}$, Keen $\mathrm{H}$. The impact of cardiovascular disease on people with diabetes: the potential for prevention. Lancet. 1997;350:S29-32.

11. Lewis GF, Steiner G. Hypertriglyceridemia and its metabolic consequences as a risk factor for atherosclerotic cardiovascular disease in non-insulin-dependent diabetes mellitus. Diabetes Metab Rev. 1996;12(1):37-56.

12. Krauss RM. Heterogeneity of plasma low-density lipoproteins and atherosclerosis risk. Curr Opin Lipidol. 1994;5(5):339-49.

13. Danquah I, et al. Diabetes mellitus type 2 in urban Ghana: characteristics and associated factors. BMC Public Health. 2012;12(1):210.

14. Saeed BI, et al. The effect of socio-economic predictors of chronic diseases in Ghana: results of a nationwide survey. Glob J Health Sci. 2013;5(5):115.

15. Reed HE, Andrzejewski CS, White MJ. Men's and women's migration in coastal Ghana: an event history analysis. Demogr Res. 2010. https://doi. org/10.4054/DemRes.2010.22.25.

16. Alhassan RK, et al. Perceived needs of health tutors in rural and urban health training institutions in Ghana: implications for health sector staff internal migration control. PLOS ONE. 2017;12(10):e0185748. 
17. Sanuade $O A$, et al. Patterns of cardiovascular disease mortality in Ghana: a 5-year review of autopsy cases at Korle-Bu Teaching Hospital. Ethn Dis 2014;24(1):55-9.

18. Chen S-C, Tseng C-H. Dyslipidemia, kidney disease, and cardiovascular disease in diabetic patients. Rev Diabet Stud RDS. 2013;10(2-3):88.

19. Albai $\mathrm{O}$, et al. Characteristics of the lipid profile in patients with diabetes mellitus and chronic kidney disease. Romanian J Diabetes Nutr Metab Dis. 2017;24(3):237-45.

20. Chobanian AV, et al. Seventh report of the joint national committee on prevention, detection, evaluation, and treatment of high blood pressure. Hypertension. 2003;42(6):1206-52

21. Association, G.A.o.t.W.M. World Medical Association Declaration of Helsinki: ethical principles for medical research involving human subjects. J Am Coll Dent. 2014;81(3):14.

22. Wilson PW, et al. Prediction of coronary heart disease using risk factor categories. Circulation. 1998;97(18):1837-47.

23. Friedewald WT, Levy RI, Fredrickson DS. Estimation of the concentration of low-density lipoprotein cholesterol in plasma, without use of the preparative ultracentrifuge. Clin Chem. 1972;18(6):499-502.

24. European Guidelines on cardiovascular disease prevention in clinical practice (version 2012). The Fifth Joint Task Force of the European Society of Cardiology and Other Societies on Cardiovascular Disease Prevention in Clinical Practice (constituted by representatives of nine societies and by invited experts). Developed with the special contribution of the European Association for Cardiovascular Prevention \& Rehabilitation (EACPR). European J Prev Cardiol. 2012;19(4):585-667.

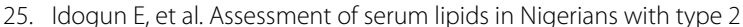
diabetes mellitus complications. Pak J Med Sci. 2007;23(5):708.

26. Khoo K, Tan H, Liew Y. Serum lipids and their relationship with other coronary risk factors in healthy subjects in a city clinic. Med J Malaysia. 1997:52(1):38-52.

27. Schofield JD, et al. Diabetes dyslipidemia. Diabetes Ther. 2016;7(2):203-19.

28. Mooradian AD. Dyslipidemia in type 2 diabetes mellitus. Nat Rev Endocrinol. 2009;5(3):150.
29. Zhao W-H, et al. Blood lipid profile and prevalence of dyslipidemia in Chinese adults. Biomed Environ Sci BES. 2007;20(4):329-35.

30. McDonald M, et al. Prevalence, awareness, and management of hypertension, dyslipidemia, and diabetes among United States adults aged 65 and older. J Gerontol Ser A Biomed Sci Med Sci. 2009;64(2):256-63.

31. Joshi SR, et al. Prevalence of dyslipidemia in urban and rural India: the ICMR-INDIAB study. PLoS ONE. 2014;9(5):e96808.

32. Brunzell JD, et al. Lipoprotein management in patients with cardiometabolic risk: consensus conference report from the American Diabetes Association and the American College of Cardiology Foundation. J Am Coll Cardiol. 2008;51(15):1512-24.

33. Siegel RD, et al. Lipoproteins, apolipoproteins, and low-density lipoprotein size among diabetics in the Framingham offspring study. Metab Clin Exp. 1996;45(10):1267-72.

34. Garg A. Insulin resistance in the pathogenesis of dyslipidemia. Diabetes Care. 1996:19(4):387-9.

35. Paschos P, Paletas K. Non alcoholic fatty liver disease and metabolic syndrome. Hippokratia. 2009;13(1):9.

36. Bugianesi E, McCullough AJ, Marchesini G. Insulin resistance: a metabolic pathway to chronic liver disease. Hepatology. 2005:42(5):987-1000.

37. Mesotten D, et al. Contribution of circulating lipids to the improved outcome of critical illness by glycemic control with intensive insulin therapy. J Clin Endocrinol Metab. 2004;89(1):219-26.

38. Tames FJ, et al. Non-enzymatic glycation of apolipoprotein B in the sera of diabetic and non-diabetic subjects. Atherosclerosis. 1992;93(3):237-44.

39. Berneis KK, Krauss RM. Metabolic origins and clinical significance of LDL heterogeneity. J Lipid Res. 2002;43(9):1363-79.

40. Amoah AG, Owusu SK, Adjei S. Diabetes in Ghana: a community based prevalence study in Greater Accra. Diabetes Res Clin Pract. 2002;56(3):197-205.

41. The Emerging Risk Factors, C. Diabetes mellitus, fasting blood glucose concentration, and risk of vascular disease: a collaborative meta-analysis of 102 prospective studies. Lancet. 2010;375(9733):2215-22.
Ready to submit your research? Choose BMC and benefit from:

- fast, convenient online submission

- thorough peer review by experienced researchers in your field

- rapid publication on acceptance

- support for research data, including large and complex data types

- gold Open Access which fosters wider collaboration and increased citations

- maximum visibility for your research: over $100 \mathrm{M}$ website views per year

At $\mathrm{BMC}$, research is always in progress.

Learn more biomedcentral.com/submissions 